\title{
Age Specific Role of Myostatin Intron-2 Gene on Body Weight of Magra Sheep
}

\author{
Govind Singh Dhakad ${ }^{1}$, Gyanchand Gahlot ${ }^{1}$, Vijay Kumar Agrawal ${ }^{1 *}$, H.K. Narula ${ }^{2}$, \\ Jaiprakash Khicher ${ }^{1}$ and Hemlata Chouhan ${ }^{1}$ \\ ${ }^{1}$ Molecular Genetics Laboratory, Department of Animal Genetics and Breeding, College of Veterinary and Animal Science, \\ Bikaner, Rajasthan, INDIA \\ ${ }^{2}$ Department of Animal Genetics and Breeding, Central Sheep and Wool Research Institute, Arid Region Campus, Bikaner, \\ Rajasthan, INDIA \\ "Corresponding author: VK Agrawal; E-mail: drvijayvet2016@rediffmail.com
}

Received: 25 May, 2020

Revised: 17 July, 2020

Accepted: 21 July, 2020

\begin{abstract}
The economic success of small ruminant based livestock production system depends on the factors affecting the muscular growth. Therefore, the present study was carried out in one of the potential ovine meat genotype, i.e., Magra sheep breed, to investigate the role of growth regulating myostatin $(M S T N)$ gene on body weight of Magra lambs at different stages through single nucleotide polymorphisms (SNP's) based marker.Genomic DNA was isolated from whole blood of randomly selected Magra sheep (N=74) maintained at Livestock Research Farm, CSWRI, Bikaner campus through spin column method. A $311 \mathrm{bp}$ fragment comprising intron 2 region of $M S T N$ gene was amplified through designed homologous primers (GenBank accession number JN856480) at an annealing temperature of $54^{\circ} \mathrm{C}$. Initial screening of collected specimen was carried out through single stranded conformation polymorphism (SSCP) based marker on $8 \%$ non-denaturing polyacrylamide gels to detect the polymorphic individuals. Sequencing and clustal analysis was carried out in order to detect SNP's responsible for genetic variation among individuals. The three conformational patterns detected were observed to be the result of substitution of five different nucleotides substitution in the amplified fragment. Association analysis revealed significant role of heterozygotic SNP's conformation (CTAAA/TATGT) on body weight of Magra sheep at 3 and 6 months of age in comparison to homozygotic genotypic pattern, TATGT/TATGT. The present study concluded that genetic variability in intron- 2 region of MSTN gene in Magra lamb significantly affects body weight at specific stages of life.
\end{abstract}

\section{HIGHLIGHTS}

(0 Single stranded conformation polymorphism (SSCP) was used for purification of MSTN gene.

0 Genetic variability in intron- 2 region of $M S T N$ gene in Magra lamb significantly affects body weight.

Keywords: Magra sheep, MSTN, SNP's, body weight

A faster growth rate in small ruminants ultimately determine their meat producing capability up to marketing age and an overall economic success of producing system (Abbasi et al., 2012). Magra breed of sheep with breeding tract in eastern and southern areas of Bikaner, and adjoining areas of Nagaur, Jhunjhunu and Churu district of Rajasthan state (Acharya, 1982) is considered as one of the best sheep breed of India as it produces heavier lamb in terms of body weight (Narula et al., 2009). Myostatin (MSTN) gene, also called Growth and Differentiation
Factor $8(G D F 8)$ a member of the transforming growth factor- $\beta$ super family, plays an important role in the regulation of muscle growth and meat quality (Zhang et al., 2012). Ovine MSTN gene is located at the end of the long arm (2q32.2 locus) of chromosome 2 (Dimitrova et al., 2016). Variation in gene structure of ovine MSTN gene

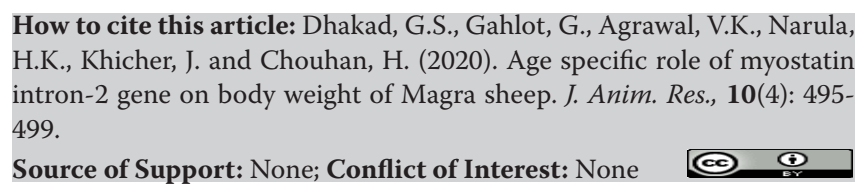


had an important role in muscular development that may regulate the expression of target genes, thereby changing the composition of muscle fibers and causing a variation of muscle weight (Chen, 2008; Elkorshy et al., 2013). The different exons of the MSTN gene were found to be highly conserved among all species (Dehnavi et al., 2012; Dimitrova et al., 2016; Agrawal et al., 2017a; Agrawal et al., 2017b) however, a number of studies in sheep reported significant impact of polymorphism in intron- 2 of MSTN gene on body weight (Dehnavi et al., 2012; Trukhachev et al., 2015) with highest estimated additive breeding value for weaning weight was observed in Baluchi sheep for genetically variable intronic region (Ansary et al., 2011).

The low sensitivity $(70 \%$ to $80 \%)$ and requirement of considerable skill and labour in SSCP marker analysis (Kunhareang et al., 2009) for detection of single nucleotide polymorphism (SNPs) suggest to adopt direct gene sequencing as the gold-standard approach and have almost $100 \%$ sensitivity for genotyping analysis (Laurie and George, 2009). The genetic diversity in Myostatin gene of Magra sheep could explain partial source of variation in growth traits. Therefore, in order to detect effective nucleotide substitution influencing body weight during initial stages of Magra lambs, the present study was designed to analyze the genetic variation in intron-2 of MSTN gene in Magra sheep through sequence analysis and their subsequent association with body weight after SSCP based screening.

\section{MATERIALS AND METHODS}

\section{Sample collection}

Contemporary and apparently healthy male Magra lambs $(n=74)$ with no history of any illness in the past six months were randomly selected from flocks with most distant genetic background on the basis of available pedigree information from Magra Sheep Farm maintained at Livestock Research Farm of CSWRI, Bikaner.The blood samples $(2 \mathrm{ml})$ were collected from jugular vein in vacutainer tubes containing EDTA as an anticoagulant. The information on body weight from birth to 6 months of age was also collected along with the respective blood samples. Uniform feeding practices with full grower ration were adapted for all the studied animals. All animals were kept in optimal ventilated conditions with proper and timely vaccination and deworming. The genomic DNA was extracted by spin column method as per manufacturer's protocol. The quality and the concentration of DNA were checked on $0.8 \%$ agarose and Nano Drop spectrophotometer, respectively.

\section{PCR amplification}

A set of amplification primer pair (F-5'CAC ATT TTT CCC CCA GAA GAG3'; R-5'AAG ACA GTT CAG AAA ATA GCT GG3') was designed based on the homologous ovine MSTN gene sequences available at NCBI BLAST (GenBank accession No. JN856480) using primer 3 software to amplify the $311 \mathrm{bp}$ fragment comprising intron2 region of MSTN gene. Amplification reactions for each fragment was done by using the following constituents: in a final volume of $25 \mu \mathrm{l}$ containing $5 \mathrm{X}$ PCR buffer $(5 \mu \mathrm{L})$, 1 unit of TaqDNA polymerase $(0.2 \mu \mathrm{L}), 10 \mathrm{mM}$ each of dNTPs $(0.5 \mu \mathrm{L}), 25 \mathrm{mM} \mathrm{MgCl}(2.5 \mu \mathrm{L}), 100 \mathrm{pMol}$ of each primer $(0.5 \mu \mathrm{L})$ and $100 \mathrm{ng}$ of template DNA $(2 \mu \mathrm{L})$. Amplification was performed in a thermal cycler with the following programme; after an initial denaturation step at $95^{\circ} \mathrm{C}$ for $5 \mathrm{~min}, 35$ cycles were programmed as follows: $94^{\circ} \mathrm{C}$ for 45 seconds, $54^{\circ} \mathrm{C}$ for 60 seconds, $72^{\circ} \mathrm{C}$ for 60 seconds and final extension at $72^{\circ} \mathrm{C}$ for $10 \mathrm{~min}$. Gradient PCR approach was adopted to determine the optimum number of cycles and annealing temperature with the use of negative controls during each batch of amplification to observe any contamination during process. The amplified DNA fragments were stained with ethidium bromide and visualized on $1.5 \%$ agarose gel under gel documentation system with standard molecular marker.

\section{Sequencing and sequence analysis}

The different SNP's responsible for genotypic conformation of MSTN intron- 2 region in Magra sheep were identified through Sanger dideoxy chain termination sequencing method and sequence analysis of at least five representative samples of each detected SSCP conformational pattern. SSCP marker based screening was carried out on $8 \%$ non denaturing polyacrylamide gels $\left(120 \mathrm{~V} / 7 \mathrm{~h} / 4^{\circ} \mathrm{C}\right)$ using denaturing solution containing $800 \mu \mathrm{L}$ formamide $(99 \%), 100 \mu \mathrm{L}$ loading dye, $100 \mu \mathrm{L}$ glycerol (98\%), $3 \mu \mathrm{L} 0.5 \mathrm{M}$ EDTA, and $2 \mu \mathrm{L} 10 \mathrm{M} \mathrm{NaOH}$. Forward and reverse sequences of each gene fragment was assembled against the most closely related reference 
sequence of respective gene to obtain total sequence length and similarity was looked into the non-redundant database with BLAST algorithms (http://www.ncbi.nlm.nih.gov/ BLAST). The nucleotide sequence of the amplified fragment was submitted to NCBI database to obtain the accession number. Multiple sequence alignment (MSA) and sequence analysis was carried out using Clustal X2 and Bioedit ( $\mathrm{v}$ 7.0.7.1) bioinformatics tools to identify SNP's between different genotypic patterns.

\section{Association analysis}

The statistical analysis for association of SNP's pattern with body weight was carried out using General Linear Model (GLM) of SPSS software ver. 20.0 (SPSS Inc., Chicago, IL, USA) by following statistical model:

$$
Y_{i j}=\mu+G_{i}+e_{i j}
$$

where, $Y_{i j}=$ body weight of the $j^{\text {th }}$ animal of $i^{\text {th }}$ genotype, $\mu=$ overall mean, $G_{i}=$ fixed effect of $i^{\text {th }}$ genotype, $e_{i j}=$ random error, NID $\left(0, \sigma^{2}\right)$.

\section{RESULTS AND DISCUSSION}

Sequencing and sequence analysis of the three conformational patterns (' $A A$ ', ' $A B$ ' and ' $B B$ ') for intron2 region of MSTN gene in Magra sheep revealed the presence of two alleles ' $A$ ' and ' $B$ ' (Fig. 1).

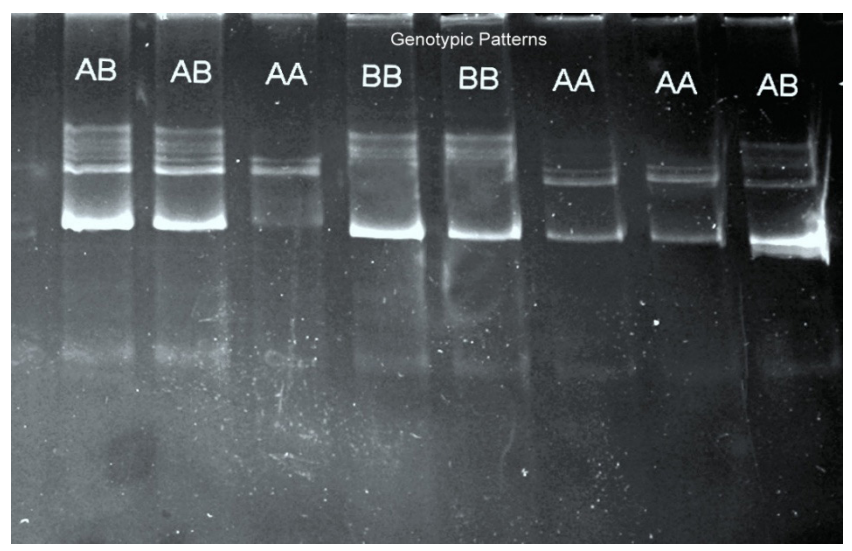

Fig. 1: SSCP conformational patterns of MSTN intron- 2 region in Magra sheep

Clustal analysis of sequenced region detected the presence of five variable nucleotides positions between allele ' $A$ '
(Accession No. MF069177) and ' $B$ ' (Accession No. MF069178) when compared with reference sequence (Gene Bank Accession no. JN856480) of Ovis aries (Fig. 2). The conformational pattern ' $A A$ ' of Magra sheep revealed $100 \%$ similarity in nucleotide sequence with the reference sequence.The number of SNP's detected in the present study was low in numbers $(n=5)$ than the seven SNP's detected by Xiang-Long et al. (2006) in the similar region.

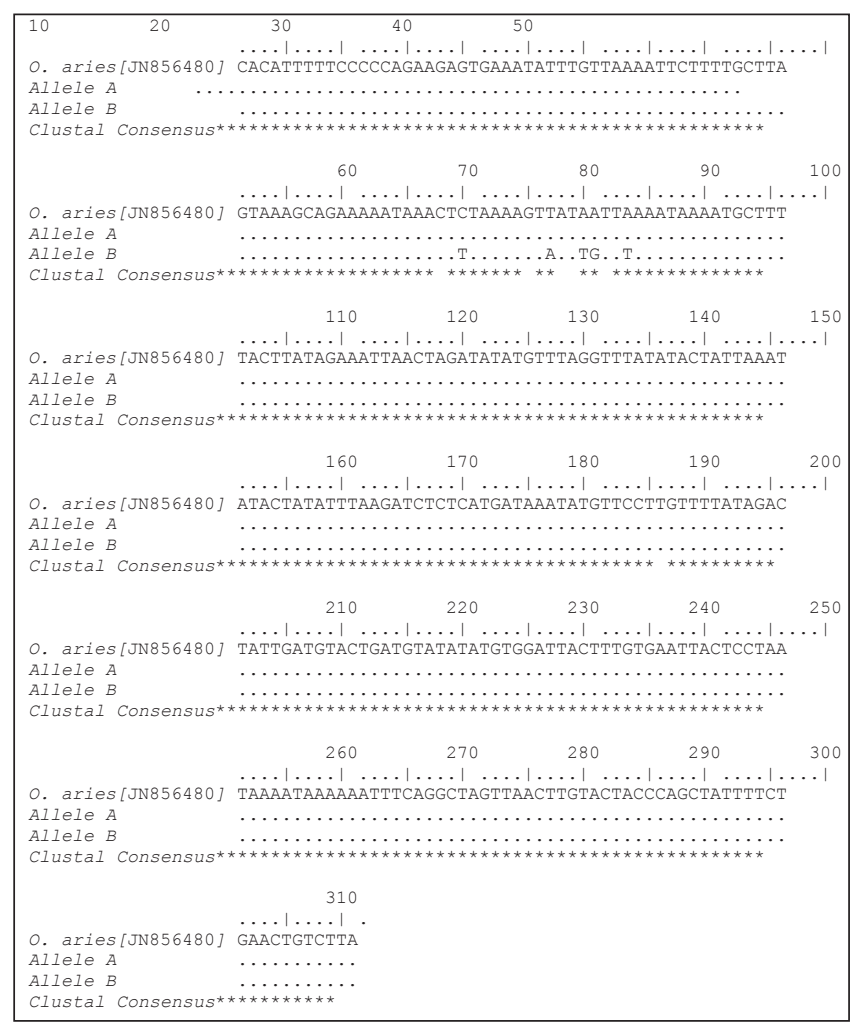

Fig. 2: Multiple Sequence Alignment and clustal analysis of intron- 2 region of MSTN gene in Magra sheep

The different SNPs observed in intron 2 region of MSTN gene in Magra sheep are depicted in Table 1. Three of the five SNP's detected were transversion whereas two detected SNP's were transition in nature. It was observed that most of the SNP's were confined within a very short nucleotide stretch from nucleotide base position 71 to 86 . Higher genetic variability in intron-2 region of MSTN gene was observed by Farhadian et al. (2011) who detected a total of fifteen SNPs in sixty animals of nine Chinese and one exotic sheep breeds. Statistical analysis for association of body weights at different stages with 
different sequenced patterns revealed age specific effect of polymorphism of MSTN intron -2 locus on body weight in Magra sheep (Table 2).

Table 1: Single nucleotide polymorphisms in intron -2 region of MSTN gene in Magra sheep

\begin{tabular}{lllll}
\hline Region & $\begin{array}{l}\text { Nucleotide } \\
\text { positions }\end{array}$ & $\boldsymbol{A} \boldsymbol{A}$ pattern & $\boldsymbol{B} \boldsymbol{B}$ pattern & Mutation \\
\hline & 71 & $\mathrm{C}$ & $\mathrm{C} \rightarrow \mathrm{T}$ & Transition \\
& 79 & $\mathrm{~T}$ & $\mathrm{~T} \rightarrow \mathrm{A}$ & Transversion \\
MSTN & 82 & $\mathrm{~A}$ & $\mathrm{~A} \rightarrow \mathrm{T}$ & Transversion \\
Intron 2 & 83 & $\mathrm{~A}$ & $\mathrm{~A} \rightarrow \mathrm{G}$ & Transition \\
& 86 & $\mathrm{~A}$ & $\mathrm{~A} \rightarrow \mathrm{T}$ & Transversion \\
\hline
\end{tabular}

Magra lambs with heterozygote genotype combination $(A B)$ revealed statistically higher body weight than lambs having recessive $(B B)$ genotype combination (TATGT/ TATGT $) \quad(\mathrm{p} \leq 0.05)$ however non-significant variation between patterns $A A$ and $A B$; and $A A$ and $B B$ suggest the role of non additive gene action in enhancing the body weight in Magra lambs. The absence of discernible variation in body weight of Magra lambs at birth among all the detected conformational patterns indicates the role of maternal effect on body weight in initial stages of life.

Table 2: Association analysis of conformational pattern of intron -2 region of MSTN gene in Magra sheep with body weight at different stages

\begin{tabular}{llllll}
\hline $\begin{array}{l}\text { Sequencing } \\
\text { Patterns }\end{array}$ & $\begin{array}{l}\text { Conformational } \\
\text { Patterns }\end{array}$ & \multirow{2}{*}{$\mathbf{N}$} & \multicolumn{3}{c}{ Body weight (Kgs) } \\
\cline { 4 - 6 } & & & Birth & 3 Month & 6 Month \\
\hline CTAAA & $A A$ & 54 & $3.28 \pm$ & $18.07 \pm$ & $24.81 \pm$ \\
CTAAA & & & 0.05 & $0.86^{\mathrm{ab}}$ & $0.54^{\mathrm{ab}}$ \\
CTAAA & $A B$ & 13 & $3.40 \pm$ & $18.90 \pm$ & $27.22 \pm$ \\
& & & 0.10 & $0.73^{\mathrm{b}}$ & $1.11^{\mathrm{b}}$ \\
TATGT & & 7 & $3.27 \pm$ & $16.21 \pm$ & $23.31 \pm$ \\
TATGT & $B B$ & & 0.14 & $1.07^{\mathrm{a}}$ & $1.52^{\mathrm{a}}$ \\
TATGT & & & & & \\
\hline
\end{tabular}

Means with different superscripts $a$ and $b$ are statistically significant in each column $(\mathrm{p} \leq 0.05)$.

\section{CONCLUSION}

The sequence information generated for MSTN gene of Magra sheep would help in better understanding of growth traits and could support in further breeding and selection strategy. The sequence comparison of MSTN intron-2 gene of Magra sheep with other species could also elucidate the mechanism of growth. The present study concluded that genetic variability in intron-2 region of MSTN gene in Magra lamb affects body weight in Magra sheep at specific stages of life and could be useful for developing marker assisted selection programmes for improving weight gain in Magra sheep.

\section{ACKNOWLEDGMENTS}

Authors are thankful to Rajasthan University of Veterinary and Animal Sciences, Bikaner (Rajasthan) for providing financial support and necessary infrastructure during M.V.Sc research work.

\section{REFERENCES}

Abbasi, M.A., Abdolllahi-Arpanahi, R., Maghsoudi, A., Vaez Torshizi, R. and Nejati-Javaremi, A. 2012. Evaluation of models for estimation of genetic parameters and maternal effects for early growth traits of Iranian Baluchi sheep. Small Rumin. Res., 104:62-69.

Acharya, R.M. 1982. Sheep and goat breeds of India. FAO Animal production and Health paper 30, Food and Agriculture Organization of the United Nation, Rome, Italy.

Agrawal, V.K., Gahlot, G.C., Ashraf, M., Khicher, J.P. and Thakur, S. 2017a. Sequence analysis and phylogenetic relationship of myostatin gene of Bikaneri camel (Camelus dromedarius). J. Camel Pract. Res., 24(1): 73-76.

Agrawal, V.K., Gahlot, G.C., Gupta, S., Yadav, S.P., Ashraf, M. and Thakur, S. 2017b. Molecular characterization of myostatin gene affecting muscle growth in Kankrej cattle. Haryana Vet., 56(1): 25-28.

Ansary, M., Tahmoorespur, M., Nassiry, M.R., Taheri, A. and Valeh, V. 2011. Polymorphism in intron-I of myostatin gene and its association with estimated breeding values of growth traits in Baluchi sheep (Ovis aries). Indian J. Anim. Sci., 81(8): 75-100.

Casas, E., Keele, J., Fahrenkrug, W.S., Smith, T.P., Cundiff, L.V. and Stone, R.T. 1998. Quantitative analysis of birth, weaning, and yearling weights and calving difficulty in Piedmontese cross breeds segregating an inactive myostatin allele. $J$. Anim. Sci., 77: 1686-1692.

Chen, T.T. 2008. Polymorphisms of MSTN, IGFBP-3 gene and the related research with growth performance of Tianfu Goat, Sichuan Agricultural University, Ya'an. Asian J. Anim. Vet. $A d v$., 7: 802-811. 
Dehnavi, E., Azari, A.M., Hasani, S., Nassiry, M.R., Mohajer,M., Khan A.A., Shah M.L. and Yousefi, S. 2012. Polymorphism of myostatin gene in intron 1,2 and exon 3 and their associations with yearling weight using PCR-RFLP and PCR-SSCP techniques in Zel sheep. Biotechnol. Res. Int., 1: $1-5$.

Dimitrova, I., Bozhilova-Sakova, M., Stancheva, N. and Tzonev, T. 2016. Molecular analysis of ovine myostatin gene (MSTN) in northeast Bulgarian Merino sheep breed using PCR-RFLP. Bulgarian J. Agric. Sci., 22(2): 1-3.

Elkorshy, N., Karima F., Mahrous and Lamiaa, M. S. 2013. Genetic polymorphism detection in four genes in Egyptian and Saudi sheep breeds. World Appl. Sci. J., 27(1): 33-43.

Farhadian, M. and Hashemi, A. 2016. Molecular characterization and phylogeny based analysis of intron I sequence of Myostatin $(M S T N)$ gene in Iranian Makuei sheep breed. Ann. Anim. Sci., 16(4): 1007-1018.

Farhadian, M., Hashemi, A., Mardani, K., Darvishzadeh, R. and Ranjbari, M. 2011. Allelic polymorphism of 'Makoei' sheep myostatin gene identified by polymerase chain reaction and single strand conformation polymorphism. African $J$. Biotechnol., 10(50): 10083-10086.

Kunhareang, S., Zhou, H. and Hickford, J.G.H. 2009. Allelic variation in the porcine MYF5 gene detected by PCR-SSCP. Mol. Biotechnol., 41: 208-212.
Laurie, A.D. and George, P.M. 2009. Evaluation of highresolution melting analysis for screening the LDL receptor gene. Clin. Biochem., 42: 528-535.

Narula, H.K., Yadav, S.B.S., Sharma, P.R. and Mehrotra, V. 2009. Growth and reproductive performance of Magra sheep of Rajasthan. Ind. J. Anim. Sci., 79: 639-641.

Sepahvanda, F., Khaldarib, M., Beigi-Nasiria, M.T. and Fayazia, J. 2014. The study of polymorphism in intron I of myostatin gene (MSTN) and its association with growth traits in Lory sheep breed. J. Genet. Photon, 115: 141-145.

Trukhachev, V., Belyaev., Kvochko, A., Kulichenko, A., Kovalev, D., Sergey, P., Volynkina, A., Selionova, M., Aybazov, M., Shumaenko, S., Omarov, A., Mamontova, T., Golovanova, T. and Yatsyk, O. 2015. Myostatin gene (MSTN) polymorphism with a negative effect on meat productivity in Dzhalginsky Merino sheep breed. J. Biosci. Biotechnol., 4(2): 191-199.

Xiang-Long, L., Zhao-Long, W., Zheng-Zhu, L., Yuan-Fang, G., Rong-Yan, Z. and Gui-Ru, Z. 2006. SNP identification and analysis in part of intron 2 of goat MSTN gene and variation within and among species. J. Heredity, 97(3): 285-289.

Zhang, C., Liu, Y., Xu, D. and Wen, Q. 2012. Polymorphisms of myostatin gene (MSTN) in four goat breeds and their effects on Boer goat growth performance. Mol. Biol. Reprod., 39: 3081-3087. 
